\title{
TEKNOLOGI PENGOLAHAN AIR GAMBUT ASIN MENJADI AIR SIAP MINUM DI KELURAHAN TANJUNG TENGAH, PENAJAM, KALIMANTAN TIMUR
}

\author{
Peat Salt Water Treatment Technology to be Drinkable Water in Panajam \\ Oleh : \\ Imam Setiadi dan I Putu Angga Kristyawan \\ Pusat Teknologi Lingkungan, BPPT \\ Jl. M.H. Thamrin No. 8 Gd. II Lt. 18 Jakarta 10340
}

\begin{abstract}
Abstrak
Kurangnya ketersediaan air bersih di Kelurahan Tanjung Tengah, Kecamatan Penajam, Kabupaten Penajam paser Utara, Kaltim menyebabkan mahalnya harga air bersih menjadi Rp. 60.000,00 per $\mathrm{m}^{3}$. Air baku di kelurahan Tanjung Tengah memiliki kadar Fe yang tinggi yaitu 388 mg/L dan nilai TDS sebesar 12930 mg/L. Untuk mengatasi permasalahan ini maka dilakukanlah pemasangan teknologi pengolahan air gambut asin menjadi air siap minum di daerah kelurahan Tanjung Tengah. Teknologi pengolahan air gambut asin terdiri atas sistem koagulasi flokulasi, klarifier, penyaringan, reverse osmosis dan sistem distribusi. Hasil pengolahan air baku menunjukkan bahwa efisiensi sistem pengolahan mencapai 99\%. Dimana kandungan besi air olahan bernilai < 0,003 mg/L, dengan nilai TDS 77 mg/L. Air hasil olahan juga telah dinyatakan memenuhi standar baku mutu air minum.
\end{abstract}

Kata Kunci : air bersih, air gambut asin, reverse osmosis, besi dan TDS.

\section{Abstract}

Low levels of clean water supply in the Tanjung Tengah village causing the high price of water. value of Fe and TDS in the village raw water is high. The value of Fe content is 388 $\mathrm{mg} / \mathrm{L}$ and TDS value is $12930 \mathrm{mg} / \mathrm{L}$. The installation of salty peat water treatment technology were done to overcome this problem. The Salty peat water treatment technology consists of coagulation flocculation system, clarifier, filtration, reverse osmosis and a distribution systems. Results showed that this treatment efficiency reaches $99 \%$. Where the iron content of the treated water is less than $0.003 \mathrm{mg} / \mathrm{L}$, with a TDS value down to be $77 \mathrm{mg} / \mathrm{L}$. The treated water also meet drinking water quality standards.

Keywords : Clean Water, Salty Peat Water, Reverse Osmosis, Iron and TDS.

\section{PENDAHULUAN}

Air bersih sangat penting untuk kehidupan manusia. Air yang tidak bersih, dapat menyebabkan penyakit seperti misalnya diare. Pada tahun 2014, nilai angka kematian akibat diare secara nasional di Indonesia mencapai $1,14 \%$. Hal ini jauh dari target pemerintah yang menginkan angka kematian kematian akibat diare dibawah 1\%. (DepkesRI,2015). Salah satu masalah yang masih dihadapi sampai saat ini yakni masih rendahnya tingkat pelayanan air bersih untuk masyarakat. Pada tahun 2012 Indonesia baru 58,05 persen masyarakat mendapatkan air minum layak dan hanya 57,35 persen rumah tangga memiliki akses sanitasi layak (Kemenpu,2013).

Beberapa permasalahan pokok yang masih dihadapi dalam penyediaan air bersih di Indonesia antara lain adalah masalah tingkat pelayanan air bersih yang masih rendah, masalah kualitas air baku dan kuantitas yang sangat fluktuatif pada musim hujan dan musim kemarau, serta masalah teknologi yang digunakan untuk proses pengolahan kurang sesuai dengan kondisi air baku yang kualitasnya cenderung makin menurun (Said, 2000).

Teknologi pengolahan air minum yang digunakan oleh Peruasahaan Air Minum (PAM) Di Indonesia umumnya masih menggunakan sistem konvesional yakni dengan sistem Koagulasi-Flokulasi (Pengendapan Kimia), Saringan Pasir Cepat (Rapid Sand Filter) dan Proses Disinfeksi mengggunakan senyawa khlorin (gas Khlor). Dengan tingginya kandungan amonia dan bakteri coli, maka kebutuhan senyawa khlorin untuk proses disinfeksi bertambah besar, dan akibatnya kemungkinan terbentuknya 
senyawa THMs dan senyawa halogen organik lainnya juga bertambah besar. Demikian juga dengan adanya kandungan phenol yang cukup besar. Dengan adanya pembubuhan khlorin, phenol akan dengan mudah bereaksi dengan senyawa khlor membentuk senyawa halogen organik Khlorophenol yang sangat berbahaya. Masalah THMs ini perlu diperhatikan secara serius karena THMs adalah senyawa yang secara potensial dapat menyebabkan kanker (Said,1999).

Untuk wilayah perkotaan di daerah pesisir, di daerah yang terpengaruh oleh pasang surut atau wilayah perkotaan di pulau-pulau kecil, masalah kualitas air baku air minum sering menjadi masalah yang sangat besar. Umumnya teknologi pengolahan air minum yang digunakan oleh PAM atau PDAM dirancang untuk mengolah air baku yang tidak asin atau sesuai dengan baku mutu air Golongan B yakni peruntukan air baku air minum dengan konsentrasi TDS maksimum 1000 mg/l. Jika konsentrasi TDS melebihi standar maksimum yang diperbolehkan dapat dipastikan proses pengolahan tidak dapat berjalan dengan baik, karena teknologinya memang tidak dirancang untuk kondisi dengan konsentrasi TDS yang tinggi atau untuk air payau/asin (Said, 2000).

Selain masalah kualitas air baku air minum yang semakin buruk, masalah serius yang diahadapi oleh peruasahan air minum (PAM) di Indonesia yakni masalah ketersediaan air baku air minum. Akibat perubahan tataguna lahan di daerah hulu sampai hilir mengakibatkan fluktuasi debit air pada musim hujan dan muasim kemarau sangat besar. Hal mengakibatkan penurunan yang sangat tajam terhadap debit air sungai untuk air baku air minun pada musim kemarau. Penurunan debit air sungai pada musim kemarau tersebut juga mengakibatkan konsentrasi polutan yang ada dalam air sungai menjadi lebih pekat yang berakibat terhadap kualitas air minum yang dihasilkan serta naiknya biaya proses pengolahan air minum (Said, 2000).

Permasalahan tentang pasokan air bersih, juga terjadi di Kelurahan Tanjung Tengah, Kecamatan Penajam, Kabupaten Penajam paser Utara, Kaltim. Daerah ini memiliki jumlah penduduk sekitar 2000 jiwa (Kemenpu, 2013). Peduduk Kelurahan tersebut menggunakan air hujan untuk kembutuhan air minum serta mandi cuci atau dengan cara membeli air bersih menggunakan truk tangki dengan harga yang rekatif mahal yakni Rp. 60.000,- per meter kubik. Air tanah diwilayah tersebut sudah terpengaruh oleh intrusi air laut dan mengandung gambut serta mengandung zat besi yang cukup tinggi.

Untuk dapat mengolah air laut menjadi air bersih dapat menggunakan teknologi reverse osmosis (RO). Teknologi ini dapat menurunkan kadar garam dalam air 95 - 98\% (Said, 2003). Teknologi pengolahan air asin atau payau menggunakan RO juga telah dipasangkan dibeberapa daerah di Indonesia. Antara lainnya di kepulauan seribu, palembang dan cilacap. Pengolahan ini mampu memberikan hasil yang maksimal untuk kapasitas 7,5 $\mathrm{m}^{3}$ /hari hingga $10 \mathrm{~m}^{3} /$ hari (kelair, 2000). Dengan kapasitas dan efisiensi yang tinggi, teknologi RO menjadi suatu pilihan teknologi yang tepat untuk diterapkan di Penajam. Oleh karena itu kegiatan ini bertujuan menerapkan teknologi reverse osmosis untuk mengatasi permasalahan air bersih di penajam. Sehingga masyarakat akan mampu menikmati air bersih dengan harga yang murah.

\section{PELAKSANAAN KEGIATAN}

Lokasi pemasangan pilot plant terletak di provinsi Kalimantan Timur, Kabupaten Penajam Paser Utara, Kecamatan Penajam, Kelurahan Tanjung Tengah. Pemasangan pilot plant pengolahan air gambut asin penajam menjadi air bersih dilakukan melalui beberapa tahapan. Tahapan yang dilakukan antara lain survey kualitas air baku, pemasangan unit pretreatment, treatment dan unit distribusi hasil pengolahan air.

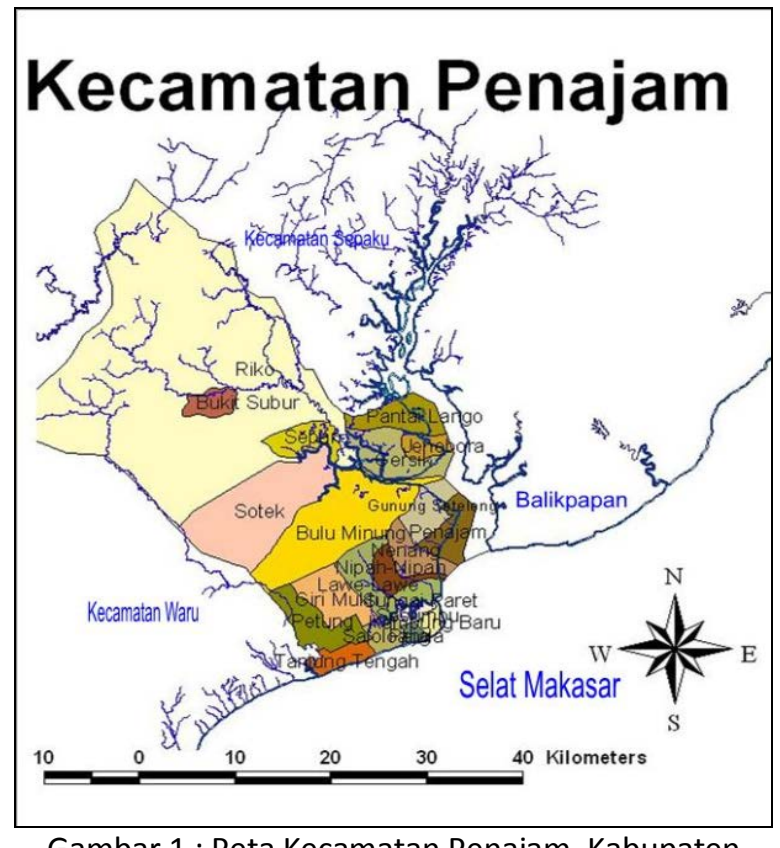

Gambar 1 : Peta Kecamatan Penajam, Kabupaten

Penajam Paser Utara, Kalimantan Timur

\subsection{Kualitas Air Baku Kelurahan Tanjung Tengah, Kabupaten Penajam Paser Utara}

Air baku utama yang digunakan berasal dari dua sumber, yaitu sumber air permukaan berupa kolam penampung air baku dan sumur bor air tanah pada kedalaman 30 meter. Air baku Kelurahan Tanjung Tengah Kab.Penajam Passer Utara yang akan 
diolah berasal dari sungai Tunan yang berasa asin dengan kandungan padatan terlarut berkisar 32.000 ppm.

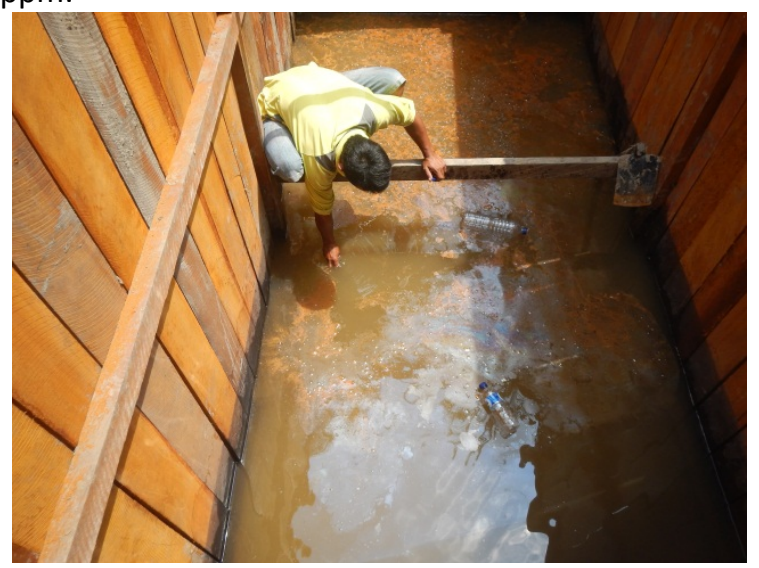

Gambar 2 : Air Tanah Dangkal di Kelurahan Tanjung Tengah, Kecamatan Penajam.

\subsection{Flow Diagram Pengolahan air asin Penajam}

Air baku dipompake tangki pengendap awal sambil diberikan larutan kapur, tawas, dan PAC. Kapur digunakan untuk menjaga keasaman air agar tetap netral yaitu pada kisaran 6 - 7sehingga proses menggumpalkan koloida pada air baku oleh tawas dan PAC dapat tereaksikan dengan sempurna. Air kemudian mengalir menuju bak pengendap dan selanjutnya masuk ketangki penampung air baku.Dari tangki air baku air disaring olehsaringan pasirsekaligus diinjeksi denganlarutan kaporit dengan menggunakan pompa kimia, agar zat besi atau mangan yang larut dalam air baku dapat dioksidasi menjadi bentuk senyawa oksida Besi (Fe) atau Mangan ( $\mathrm{Mn}$ ) yang tak larut dalam air sehingga dapat disaring pada saringan pasir. Selain itu, pemberian kaporit berfungsi untuk membunuh mikroorganisme dan bakteri yang terdapat pada air baku, yang dapat menyebabkan biofouling ( penyumbatan oleh mikroba ) di kulit membran juga sebagai bahan aktivasi media manganese zeolite.

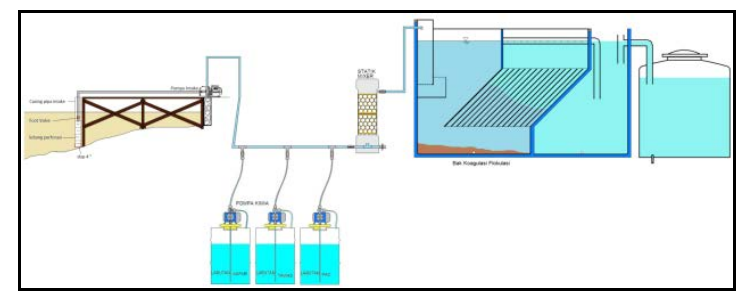

Gambar 3 : Flow diagram unit pretreatment.

Air yang telah di oksidasi kaporit dan juga padatan tersuspensi (SS) yang berupa partikel halus, plankton dan lainnya selanjutnya dapat disaring pada saringan pasir cepat ( sand filter). Air yang keluar dari saringan pasir selanjutnya dialirkan ke filter Mangan Zeolit (manganese greensand filter). Dengan adanya filter Mangan Zeolit ini, zat besi atau mangan yang belum teroksidasi dapat dihilangkan sampai konsentrasi < 0,1 mg/l. Zat Besi dan Mangan ini harus dihilangkan terlebih dahulu karena zat-zat tesebut dapat menimbulkan kerak (scale) pada kulit membran.

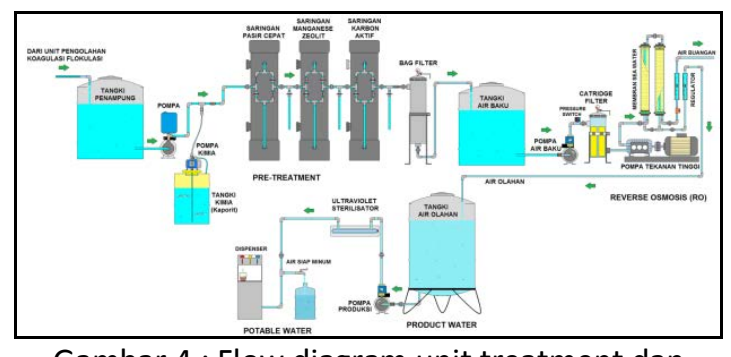

Gambar 4 : Flow diagram unit treatment dan distribusi.

Dari filter Mangan Zeolit, air dialirkan ke filter karbon aktif (activated carbon filter) untuk menghilangkan bau atau warna serta polutan mikro. Filter ini mempunyai fungsi untuk menghilangkan senyawa warna dan bau pada air baku, kemudian air ditampung pada tangki air olahan. Kemudian air ini diolah kembali pada unit ultrafiltrasi sehingga air tersebut dapat layak dikonsumsi sebagai air bersih dan ditampung pada tangki air bersih.

Untuk di tingkatkan kualitas air bersih menjadi air siap minum air bersih tersebut kemudian dialirkan dengan pompa umpan menuju sistem reverse osmosis melalui cartridge filter yang dapat menyaring partikel kotoran sampai ukuran 0,5 mikron. Dari filter cartridge, selanjutnya, air dialirkan ke unit membrane RO dengan menggunakan pompa tekanan tinggi. Air yang keluar dari modul membran Osmosa Balik yakni air tawar dan air buangan dengan TDS tinggi. Selanjutnya produk air proses dengan TDS rendah dialirkan ke tangki penampung air produk yang terbuat dari bahan stainles steel. Sedangkan air buangangan atau reject dikembalikan ke tangki air bersih.Dari tangki penampung air produk, sebelum ke kran pengisian air di alirkan ke filter cartridge untuk air produk dengan menggunakan pompa, selanjutnya dilewatkan ke sterilisator Ultra Violet dan selanjutnya ke kran pengisian.

\subsection{Unit Pretreatment Pengolahan air asin Penajam}

Unit pretreatment pengolahan air gambut asin Panajam terdiri atas sistem intake, unit koagulasi flokulasi, klarifier serta .

\subsubsection{Sistem Intake}

Di kelurahan Tanjung Tengah, Kecamatan Penajam sistim intake yang direncanakan adalah didermaga singgah kapal nelayan penduduk, lokasi ini bersebelahan dengan bangunan pelindung Arsinum yang akan dipasang. Sumber yang tersedia adalah muara sungai Tunan dengan lebar 400 meter dengan kedalaman 18 meter, pengaruh pasang surut +/- 2-3 
meter dari tepi sungai,kondisi fisik air berwarna kekuningan dengan sedikit lumpur, total padatan terlaut ( Total Dissolved Solid) berkisar 32.000 ppm.

Rancangan sistem intake yang akan diterapkan adalah, dimana pipa intake diletakan ditepi Jeti atau dermaga kayu bagian atas agar mudah ketika instalasi dan perawatan. Pipa intake yang menghisap air masuk kedalam sungai dilengkapi foot valve agar ketika pompa berhenti beroperai air pada pipa intake tidak terisi udara yang menyebabkan kavitasi pada pompa. Pipa intake ini juga dibungkus oleh pipa dengan diameter lebih besar atau diberi casing. Casing sistem intake diletakkan $50 \mathrm{~cm}$ dari bagian dasar sumur pengambilan, dimaksudkan untuk menjaga kebuntuan strainer pompa dari endapan sungai. Pipa yang digunakan diameter 1 " merek Rucika dengan panjang +/- 50 meter, untuk casing intake menggunakan pipa Wavin 4 " AW sepanjang 8 meter berlubang ( Perforated) berfungsi menyisihkan polutan makro.

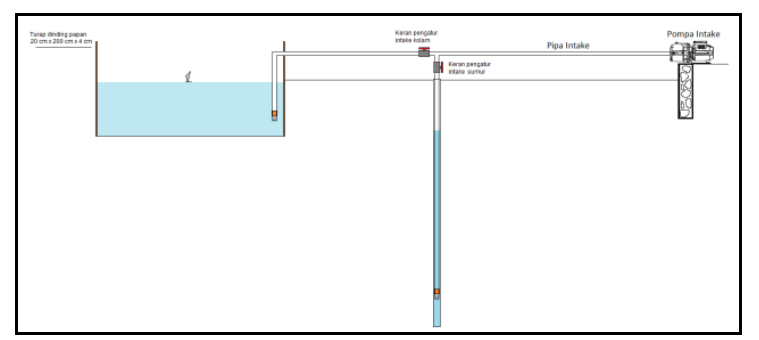

Gambar 5 : Rancangan sistem intake Arsinum Kel.Tanjung Tengah.

\subsubsection{Unit Koagulasi Flokulasi dan Klarifier}

Air baku dari air permukaan umumnya mengandung partikel tersuspensi. Partikel tersuspensi dalam air dapat berupa partikel bebas dan koloid dengan ukuran yang sangat kecil, antara 0,001 mikron (10 - $6 \mathrm{~mm}$ ) sampai 1 mikron (10 - 3 $\mathrm{mm}$ ). Partikel tersuspensi sangat sulit mengendap langsung secara alami.

Sebagai cara untuk mengatasi hal tersebut diperlukan proses pembubuhan bahan kimia koagulasi, flokulasi (penggumpalan ) dan sedimentasi (pengendapan). Proses pengendapan merupakan kelanjutan dari proses koagulasi/flokulasi, pada tahap ini terjadi pemisahan gumpalan-gumpalan kototran dari air bersih dengan cara gravitasi. Endapan yang terkumpul di dasar bak secara periodik dibuang, sementara air bersih yang ada dibagian atas bak disalurkan kedalam bak penampung air bersih. Pompa dosing yang digunakan berkapasitas 0,47 4,72 L/h, dengan injeksi larutan kapur kimia koagulasi tawas dan PAC. Adapun tangki klarifier berkapasitas 6 $\mathrm{m}^{3}$.

2.3.3 Unit Penyaringan Pasir Cepat, Manganese, Greensand, dan Karbon Aktif
Pada instalasi penyediaan air bersih dan air minum Kelurahan Tanjung Tengah, Kab.Penajam, air dari tangki reaktor masuk ke unit penyaringan pasir cepat dengan tekanan maksimum sekitar 4 Bar. Unit ini berfungsi menyaring partikel kasar yang berasal dari air baku dan hasil oksidasi kalium permanganat atau klorin, termasuk besi dan mangan. Unit filter berbentuk silinder dan terbuat dari bahan fiberglas. Unit ini dilengkapi dengan keran - keran yang berfungsi sebagai pengatur arah aliran, filtrasi atau backwash sehingga untuk proses pencucian balik dapat dilakukan dengan sangat sederhana, yaitu dengan hanya memutar keran tersebut sesuai dengan petunjuknya. Tinggi filter ini mencapai 120 $\mathrm{cm}$ dan berdiameter 12 inchi. Media penyaring yang digunakan berupa pasir silika dan terdiri dari 4 ukuran, yaitu lapisan dasar terdiri dari kerikil dengan diameter $2-3 \mathrm{~cm}$ dan kerikil halus dengan diameter $0,5-1 \mathrm{~cm}, 3-5 \mathrm{~mm}$, dan lapisan penyaring yang terdiri dari lapisan pasir silika dengan diameter 2 - $1 \mathrm{~mm}$ dan pasir silika halus dengan diameter partikel $1-0,5 \mathrm{~mm}$. Unit filter ini juga didisain secara khusus, sehingga memudahkan dalam hal pengoperasiannya dan pemeliharaannya. Dengan dilengkapi oleh 2 (dua) buah water moore, maka penggantian media filter dapat dilakukan dengan mudah.

Air olahan saringan pasir cepat masuk ke unit penyaringan pasir cepat yang menyaring partikel kasar yang berasal dari air baku dan hasil oksidasi kalium permanganat atau klorin, termasuk besi dan mangan. Air yang sudah melalui penyaringan pasir kemudian masuk ke unit penyaringan Maganese Zeolit. Unit ini juga sama bentuk dan ukuranya dengan filter pasir yaitu berbentuk silinder dan terbuat dari bahan PVC. Saringan ini juga dilengkapi dengan keran - keran yang berfungsi sebagai pengatur arah aliran, penyaringan, pencucian atau backwash danpembilasan sehingga untuk proses operasi dari ketiga cara operasi tadi dapat dilakukan dengan mudah dan sangat sederhana, yaitu dengan hanya memutar keran tersebut sesuai dengan petunjuknya. Tinggi filter ini mencapai $120 \mathrm{~cm}$ dan berdiameter 12 inchi.

Media isi saringan ini menggunakan pasir silika dan kerikil dengan diameter $2-3 \mathrm{~cm}$ dan kerikil halus dengan diameter $0,5-1 \mathrm{~cm}, 3-5 \mathrm{~mm}$ sebagai penyangga media sedangkan media penyaring terdiri dari lapisan maganese zeoilt berbentuk pasir berwarna hijau gelap dengan diameter $0,5 \mathrm{~mm}$. Unit filter ini juga didisain secara khusus, sehingga memudahkan dalam hal pengoperasiannya dan pemeliharaannya, saringan ini menggunakan pipa PVC dengan diameter 1 inchi sebagai sarana air masuk ( inlet ) dan air keluar ( outlet ).Dengan dilengkapi dua buah flange 4 inci maka penggantian media isian dapat dilakukan dengan mudah. Saringan 
ini juga dilengkapi saringan penahan media ( strainer ) agar tidak lolos keluar dari tabung filter. Media isian dapat keluar dan terbuang dari tabung filter dikarenakan mendapat tekanan hidrolika oleh air baku yang masuk, jika media isian banyak terbuangdapat menurunkan efektifitas atau kinerja penyaringan secara keseluruhan. Pada saat melakukan penyaringan air baku yang telah diolah pada proses sebelumnya masuk melalui pipa inlet kedalam saringan maganese zeolit , kemudian melewati media isisan lalu air yang sudah tersaring keluar melalui pipa outlet untuk kemudian masuk saringan selanjutnya unutk diproses lebih lanjut.

Selanjutnya pada unit instalasi penyediaan air bersih dan air minum Kelurahan Tanjung Tengah Kab.Penajam, air yang sudah melalui penyaringan pasir dan penyaringan Manganese Greensand masuk ke penyaringan karbon aktif disini terjadi proses penghilangan warna dan bau yang masih tertinggal pada air baku. Setelah melalui proses ini air baku sudah bersih dan siap untuk di tingkatkan kualitasnya menjadi air minum dengan menggunakan teknologi membrane reverse osmosis.

\subsection{Unit Treatment (Reverse Osmosis) Pengolahan air Gambut asin Penajam}

Pada bagian ini air yang sudah diolah pada penyaringan pendahuluan ditingkatkan kualitasnya. Pada fase ini penyaringan bukan lagi konvensional tetapi sudah ke penyaringan skala molekuler dengan menggunakan membran semipermeable atau yang kita sebut reverse osmosi selanjutnya disingkat RO. Unit ini mempunyai bagian - bagian penting untuk menunjang kinerja unit secara kesatuan ketika melakukan penyaringan, beberapa perangkat diantaranya pompa umpan, cartridge filter, pressure switch, pompa tekanan tinggi, dan membran.

\subsubsection{Pompa Umpan Unit Reverse Osmosis}

Pompa ini berfungsi memberikan pasokan air baku air bersih kepada pompa tekanan tinggi. Dikarenakan pompa tekanan tinggi hanya mempunyai kemampuan tekan yang besar tetapi kecil sekali kemampuan hisapnya, sehingga perlu pompa tambahan sebagai pompa umpan ( Feed Pump ).

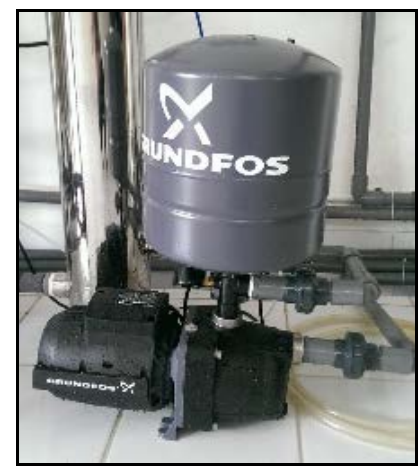

Gambar 6 : Pompa umpan

Tabel 1 : Spesifikasi Pompa Umpan

\begin{tabular}{|c|l|l|}
\hline No & Peralatan Pompa & \multicolumn{1}{|c|}{ Keterangan } \\
\hline 1 & Grundfos JP BASIC 4 & \\
& $\mathrm{Hp}$ & 1 \\
& $\mathrm{~kW}$ & $1,13 \mathrm{~kW}$ \\
& Voltase & $220-240 \mathrm{~V}$ \\
& Total Head & $42 \mathrm{~m}$ \\
& Kapasitas & $0.4-3.6 \mathrm{~m} 3 / \mathrm{h}$ \\
\hline
\end{tabular}

\subsubsection{Cartridge Filter Unit Reverse Osmosis}

Cartidge filter berfungsi sebagai penyaring partikel atau material halus yang lolos dari pengolah pendahuluan yang mempunyai ukuran lebih kecil dari 100 micron. Isi cartridge berukuran 3 x 20 Inchi. Casing filter ini terbuat dari stainless steel anti karat,berisi 3 buah media cartridge dengan ukuran pori-pori 10 micron.

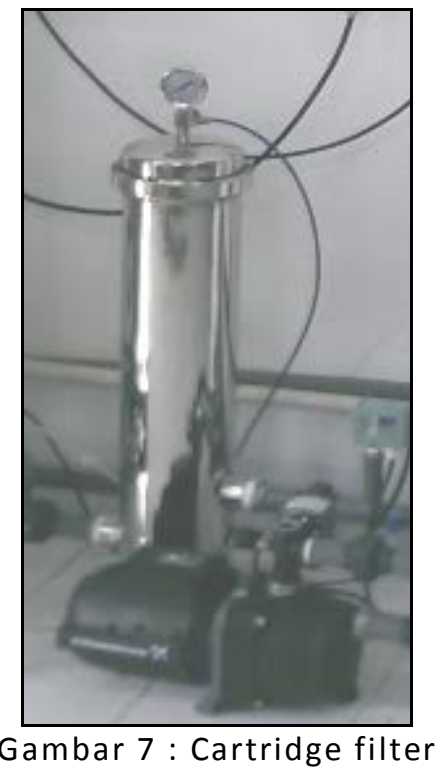

\subsubsection{Pressure Switch Unit Reverse Osmosis}

Peralatan ini berfungsi mematikan sistem apabila tejadi tekanan melebihi kemampuan operasional vessel membrane terutama mematikan pompa tekanan tinggi. Sehingga tidak merusak pompa dan peralatan lainnya.

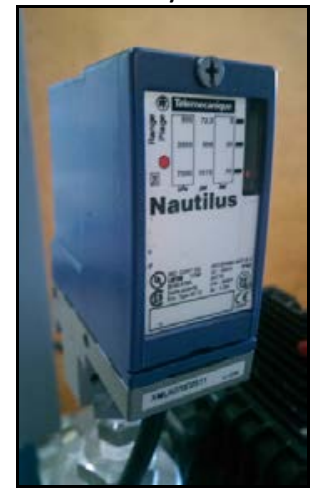

Gambar 8 : Pressure Switch 
Tabel 2 : Spesifikasi Pressure Switch

\begin{tabular}{|c|l|l|}
\hline No & \multicolumn{1}{|c|}{$\begin{array}{c}\text { Peralatan Pressure } \\
\text { swtich }\end{array}$} & \multicolumn{1}{|c|}{ Keterangan } \\
\hline 1 & Telemecanique & \\
& Nautilus & SS 316 \\
& Range & $5-70$ bar \\
& Voltase & $220-240 \mathrm{~V}$ \\
& Inlet Outle & $1 / 4$ Inci \\
\hline
\end{tabular}

\subsubsection{Pompa Tekanan Tinggi Unit Reverse Osmosis}

Pompa Tekanan Tinggi digunakan untuk mengalirkan air dari sistem pengolahan pendahuluan ke sistem penyaringan membrane RO. Untuk menembus membran osmosa balik membutuhkan tekanan besar.Air baku air tawar dalam hal ini air sungai tekanan yang dibutuhkan berkisar $40-55 \mathrm{~kg} /$ $\mathrm{cm}^{2}$. Tegangan listrik yang dibutuhkan oleh pompa ini adalah 380 Volt (3 phasa). Pompa ini bertipe plunger dengan tekanan input minimal $2 \mathrm{~kg} / \mathrm{cm}^{2}$ untuk memastikan pompa tekanan tinggi ini medapat pasokan air dari unit pretreament, maka dipasang safety pressure atau pengaman tekanan pompa pada pipa inlet. Alat ini akan bekerja memutus aliran listrik apabila pompa tidak mendapat pasokani air sebesar $2 \mathrm{~kg} / \mathrm{cm}^{2}$ dari pompa umpan.

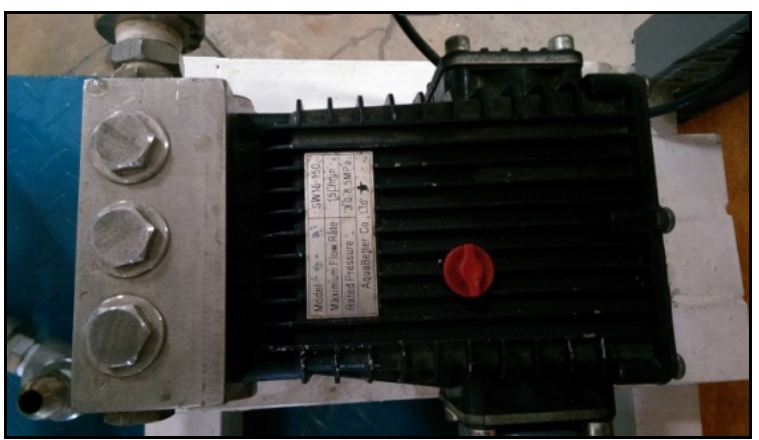

Gambar 9 : Pompa Tekanan Tinggi

Tabel 3 : Spesifikasi Pompa Tekanan Tinggi

\begin{tabular}{|l|l|l|}
\hline No & \multicolumn{1}{|c|}{ Peralatan Pompa } & \multicolumn{1}{|c|}{ Keterangan } \\
\hline 1 & Aquabetter & \\
& SW & $15-150$ \\
& Kapasitas & $15 \mathrm{l} / \mathrm{m}$ \\
& Tekanan & $3,0-8,5 \mathrm{MPa}$ \\
2 & Motor Penggerak & \\
& Siemens & $4 \mathrm{~kW}$ \\
& Voltase & $400 \mathrm{Volt} 3$ Phase \\
& Ampere & $8,4 \mathrm{~A}$ \\
\hline
\end{tabular}

\subsubsection{Membran Unit Reverse Osmosis}

Membran osmosa balik merupakan peralatan utama dari sistem pengolahan air secara keseluruhan. Unit ini terdiri dari selaput membran yang digulung secara spiral dengan pelindung kerangka luar (vessel) yang tahan terhadap tekanan tinggi.
Tabel 4 : Spesifikasi Membran Unit Reverse Osmosis

\begin{tabular}{|l|l|l|}
\hline No & Peralatan Membran & \multicolumn{1}{|c|}{ Keterangan } \\
\hline 1 & CSM & \\
& Tipe & RE $4040 \mathrm{SHN}$ \\
& Kapasitas & $4,5 \mathrm{~m} 3 / \mathrm{hr}$ \\
& Tekanan maximum & $8,27 \mathrm{MPa}$ \\
& CIP pH Range & $1.0-13.0$ \\
& Jumlah & 2 buah \\
\hline
\end{tabular}

\subsection{Unit Distribusi Pengolahan air asin Penajam}

Air hasil pengolahan sistem osmosa balik ini ditampung pada tangki penampung, tangki ini terbuat dari satinless steel dengan kapasitas $1,2 \mathrm{~m}^{3}$. Setelah ditampung maka air ini akan didistribusikan untuk proses produksi. Untuk menjaga agar air yang sudah siap minum tersebut dari kontaminasi mikroba akibat kontak dengan udara luar maka sebelum didistribusikan, air olahan tersebut diserilkan melalui unit ultraviolet.

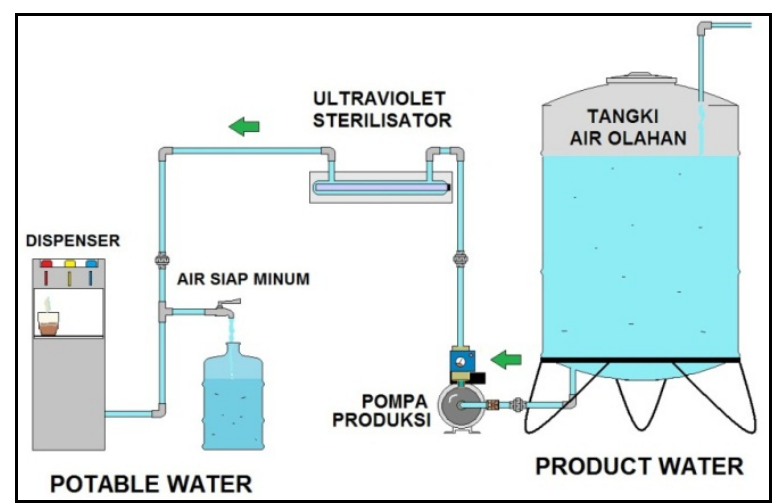

Gambar 10 : Unit distribusi pengolahan air gambut asin.

\subsection{Operasional Unit Osmosa Balik}

Urut-urutan langkah yang dilaksanakan pada permulaan pengoperasian sistem RO dapat diuraikan sebagai berikut :

1. Hidupkan pompa air baku dengan memutar selektor pompa ke posisi On pada panel utama unit osmosa balik.

2. Jika tekanan air baku mencapai 2 bar (pada penunjuk tekanan bagian depan bawah panel RO)maka selenoid bekerja dan air akan mengisi tabung membran, ditandai dengan mengalirnya air melalui flowmeter air buangan, biarkan sampai gelembung udara habis terbuang.

3. Hidupkan pompa tekanan tinggi, putar selektor searah jarum jam, posisi On

4. Kemudian putar searah jarum jam keran pengatur air buangan pada flowmeter air buangan atau reject, perhatikan juga penunjuk tekanan operasi ( disebelah penunjuk tekanan air baku). 
5. Dengan memutar keran reject maka akan tekanan operasional pada membran akan naik, pada tekanan 3 - 5 bar, unit sudah mulai mengeluarkan air olahan atau produksi.

6. Tingkatkan secara perlahan kompresi membran hingga tercapai kompresi ideal berkisar 40 - 55 bar, pada tekanan ini air produk yang dihasilkan unit dapat mencapai 6-10 LPM (liter per menit).

7. Pada tahap ini operator juga harus memperhatikan faktor kesetimbangan antara air buangan dan air produk sebaiknya jangan melebihi $50 \%$, ini untuk menjaga agar konsentrasi padatan terlarut yang tertahan oleh membran dapat terbuang seluruhnya terbawa oleh air buangan.

8. Apabila tangki penampung air produk penuh maka level kontrol akan mematikan unit osmosa balik, putar selektor pompa baku dan pompa tekanan tinggi kebalikan arah jarum jam.

9. Siapkan galon beserta tutup galon yang akan diisi pastikan sudah dibilas dengan air produk RO.

10. Hidupkan pompa produksi melalui box mcb, ini juga akan menghidupkan unit ultraviolet, buka keran utama air produksi isi galon sampai batas leher botol, tutup, simpan ditempat sejuk. Air siap didistribusikan.

\subsection{Hasil Uji Laboratorium Kualitas Air Olahan}

Analisis fisika, kimia dan mikrobiologi dilakukan atas air baku dan air hasil olahan. Pengujian dilakukan berdasarkan baku mutu air mineral. Perbandingan hasil pengujian dapat dilihat pada tabel 5. Efisiensi penurunan nilai TDS dan kekeruhan menggunakan sistem RO mencapai $99 \%$.

Tabel 5 : Perbandingan Kualitas Air Baku dan Air Olahan (Hasil Uji Laboratorium, 2015)

\begin{tabular}{|r|l|c|c|c|}
\hline No & Parameter & Satuan & $\begin{array}{l}\text { Air } \\
\text { Baku }\end{array}$ & $\begin{array}{l}\text { Air } \\
\text { Olahan }\end{array}$ \\
\hline 1 & Warna & Pt-Co & 3 & 4 \\
\hline 2 & Kekeruhan & $\mathrm{NTU}$ & 242 & 1 \\
\hline 3 & $\mathrm{TDS}$ & $\mathrm{mg} / \mathrm{L}$ & 12930 & 77 \\
\hline 1 & $\mathrm{Fe}$ & $\mathrm{mg} / \mathrm{L}$ & 388 & $<0.003$ \\
\hline 2 & Mn & $\mathrm{mg} / \mathrm{L}$ & 6 & $<0.003$ \\
\hline 1 & Coliform & MPN/100ml & $<2$ & $<2$ \\
\hline
\end{tabular}

Hasil uji laboratorium menyatakan bahwa kualitas air olahan telah memenuhi syarat baku mutu air minum kemasan sesuai dengan SNI 01-3553-2006 - untuk Air Mineral.

\section{KESIMPULAN}

Hal yang dapat disimpulkan dari kegiatan ini adalah telah dipasangnya sistem pengolahan air gambut asin kapasitas $10 \mathrm{~m}^{3}$ /hari di provinsi Kalimantan Timur, Kabupaten Penajam Paser Utara, Kecamatan Penajam, Kelurahan Tanjung Tengah. Efisiensi penurunan TDS dan kekeruhan menggunakan sistem pengolahan air gambut asin mencapai 99 \%. Air hasil olahan telah dinyatakan memenuhi baku mutu air minum.

\section{DAFTAR PUSTAKA}

- Kementerian Kesehatan Republik Indonesia, 2015, Profil Kesehatan Indonesia Tahun 2014, ISBN 978-602-235-911-1, Hal 147 - 150

- Kementerian Pekerjaan Umum, 2013, Buku Informasi Statistik Pekerjaan Umum 2013

- Said, N.I., 2003, Aplikasi Teknologi Osmosis Balik untuk memenuhi Kebutuhan Air Minum di Kawasan Pesisir atau Pulau Terpencil, J. Tek.Ling, P3TL-BPPT. 4(2) : 15 - 34.

- Said, N.I. dan kawan, 2008, Teknologi Pengelolaan Air Minum "Teori dan Pengalaman Praktis", Pusat Teknologi Lingkungan BPPT, ISBN : 978-979-8465-49-9, Hal 82 - 104.

- Said, N.I., 1999, Kesehatan Masyarakat dan Teknologi Peningkatan Kualitas Air, Pusat Teknologi Lingkungan BPPT, ISBN : 979-8465-172, Hal 82 - 104. 
